\title{
Modelling Details for Electric Field Simulations of Deep Brain Stimulation
}

J ohannes J ohansson, Fabiola Alonso and Karin Wårdell

The self-archived postprint version of this journal article is available at Linköping

University Institutional Repository (DiVA):

http:// urn.kb.se/ resolve?urn=urn:nbn:se:liu:diva-159328

N.B.: When citing this work, cite the original publication.

J ohansson, J ., Alonso, F., Wårdell, K., (2019), Modelling Details for Electric Field Simulations of Deep Brain Stimulation, WORLD CONGRESS ON MEDICAL PHYSICS AND BIOMEDICAL ENGINEERING 2018, VOL 1, 645-648. https:// doi.org/ 10.1007/978-981-10-9035-6_120

Original publication available at:

https:// doi.org/ 10.1007/ 978-981-10-9035-6 120

Copyright: SPRINGER

https://www.springer.com/ 


\title{
Modelling details for electric field simulations of deep brain stimulation
}

\author{
Johannes D. Johansson ${ }^{1[0000-0003-4910-0291]}$, Fabiola Alonso ${ }^{\text {[0000-0002-6896-1452] }}$ and Karin \\ Wårdell ${ }^{1[0000-0002-0012-7867]}$ \\ ${ }^{1}$ Linköping University, Linköping, Sweden \\ johannes.johansson@liu.se
}

\begin{abstract}
Deep brain stimulation is a well-established technique for symptomatic treatment of e.g. Parkinson's disease and essential tremor. Computer simulations using the finite element method (FEM) are widely used to estimate the affected area around the DBS electrodes. For the reliability of the simulations, it is important to match used simulation parameters with experimental data. One such parameter is the electric field magnitude threshold $E F_{\mathrm{t}}$ required for axon stimulation. Another is the conductivity of the perielectrode space (PES) around the electrode. At the acute stage after surgery the PES will be characterized by an increased conductivity due to inflammation and edema while the later chronic stage will be characterized by a lower conductivity due to gliosis and minor scar formation. In this study, the $E F_{\mathrm{t}}$ and the electric conductivity of the PES have been estimated by comparing FEM simulations with clinical studies of activation distance, pulse length and electrode impedance. The resulting estimates are an $E F_{\mathrm{t}}$ of $0.2 \mathrm{~V} / \mathrm{mm}$ at the common pulse width of $60 \mu \mathrm{s}$ and a chronaxie of $62 \mu \mathrm{s}$. Estimated electric conductivities for the PES are $0.14 \mathrm{~S} / \mathrm{m}$ in the acute stage and $0.05 \mathrm{~S} / \mathrm{m}$ in the chronic stage, assuming a PES width of $250 \mu \mathrm{m}$. These values are thus experimentally justified to use in FEM simulations of DBS.
\end{abstract}

Keywords: Deep brain stimulation (DBS), Finite Element Method (FEM), Electric field (EF).

\section{Introduction}

Deep brain stimulation (DBS) is an established technique for the disruption of pathologic neural overactivity in e.g. Parkinson's disease, essential tremor and dystonia. The exact mechanism of DBS is not known but it has been found to have similar clinical effects as lesioning techniques in the same targets for these disorders when a sufficiently high pulse frequency is used [1-4]. This is possibly due to depletion of neurotransmitters from the synapses of axons triggered with high frequency [5, 6] or more complex network effects from the interaction between different brain structures [7].

Typical parameters that can be changed in DBS are amplitude (voltage or current), pulse width and pulse frequency. Increasing the pulse width decreases the required amplitude for both therapeutic and side effects according to the chronaxie in the WeissLapicque model [8]. Pulse frequency has a more complicated effect where sufficiently 
high frequency as mentioned has a similar effect as lesioning while lower frequencies require a higher voltage for the effect [9] and sufficiently low frequency stimulation of e.g. 4 - $20 \mathrm{~Hz}$ on the contrary can worsen the pathological effect in overactive areas [9$11]$.

One way to estimate the tissue affected in the immediate vicinity of the active DBS contacts is to use finite element method (FEM) simulations to calculate the electric field around them [12]. The electric field magnitude $(E F)$ of $0.2 \mathrm{~V} / \mathrm{mm}$ at a pulse width of $60 \mu$ s has been used in several studies [13-15] as a threshold value for tissue activation but it has so far not been thoroughly justified.

The insertion of the DBS lead in the brain may cause a small, localized inflammation, which seems to contribute to the effect of DBS and could explain why inserting a DBS lead has clinical effect even when off [16]. Another result is that an edema will form in the immediate vicinity of the lead [17], a vicinity often called the perielectrode space (PES) $[18,19]$. The increase in tissue fluid of the edema will cause the electric conductivity of the PES to increase and thus affect the electric field around it. With time, the edema will subside and gliosis will form around the lead instead [20, 21]. However, the electric conductivity for the PES is not known for either the acute edema or the chronic gliosis, making it an unknown parameter for FEM modelling.

The aim of this paper is to calculate realistic values for the electric field magnitude threshold, including its rheobase and chronaxie, and to estimate reasonable conductivities for the perielectrode space during acute postoperative edema and later chronic gliosis formation.

\section{$2 \quad$ Methods and results}

\subsection{Estimation of activation threshold}

Alexis Kuncel et al. [22] have made an estimate of the distance, $r(\mathrm{~mm})$, from the electrode contact center to the ventrocaudal nucleus $(\mathrm{Vc})$ of the thalamus at which a certain stimulation amplitude triggers side effects from stimulation of the Vc. A pulse width of $90 \mu \mathrm{s}$ and a pulse frequency of $160 \mathrm{~Hz}$ had been used in this study. They arrived at a relation of threshold voltage, $V_{\text {th }}(\mathrm{V})$, and $r$ as

$$
V_{t h}=0.1+0.22 r^{2}
$$

and from this an effective activation distance can be calculated as

$$
r=\sqrt{\frac{V-0.1}{0.22}}
$$

giving an effective activation radius of $2.0-3.9 \mathrm{~mm}$ for amplitudes of $1-3.5 \mathrm{~V}$. Åström et al. found the average $E F$ at these distances for the different voltages to be $0.165 \mathrm{~V} / \mathrm{mm}$ [12]. This electric field magnitude threshold, $E F_{\mathrm{t}}$, can be fitted to the Weiss-Lapicque model according to 


$$
E F_{t}=E F_{\text {rheo }}\left(1+\frac{T_{\text {chr }}}{T}\right)
$$

where $E F_{\text {rheo }}$ is the rheobase $(\mathrm{V} / \mathrm{mm}), T_{\text {chr }}$ the chronaxie ( $\left.\mu \mathrm{s}\right)$ and $T$ the pulse width $(\mu \mathrm{s})$. With $T=90 \mu \mathrm{s}$ and a $T_{\text {chr }}$ for axon stimulation assumed to be $62 \mu \mathrm{s}$ after least squares fitting (lsqnonlin, Matlab, Mathworks, USA) to the average result from a clinical study by Mario Rizzone et al. (Table 2) [9], this gives an $E F_{\text {rheo }}$ of $0.165 /(1+62 / 90)$ $=0.098 \mathrm{~V} / \mathrm{mm}$. The estimated $E F_{\mathrm{t}}$ at the standard pulse width of $60 \mu \mathrm{s}$ then becomes $0.098 \cdot(1+62 / 60)=0.20 \mathrm{~V} / \mathrm{mm}$. The corresponding strength-duration curve is presented in Fig 1a.

(a)

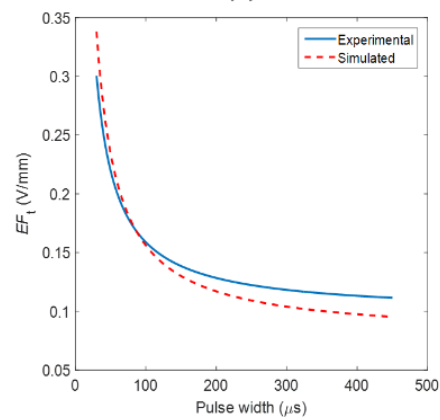

(b)

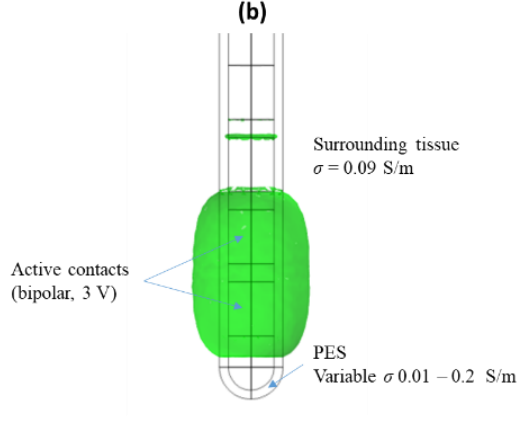

Fig. 1. (a) Strength-duration curves with chronaxies fitted to Rizzone's experimental [9] and Åström's simulated [12] data, assuming an $E F_{\mathrm{t}}$ of $0.2 \mathrm{~V} / \mathrm{mm}$ at a pulse width of $60 \mu \mathrm{s}$. (b) Three-dimensional bipolar model for estimation of PES conductivity. The green isosurface corresponds to $E F=0.2 \mathrm{~V} / \mathrm{mm}$.

\subsection{Estimation of the conductivity of the perielectrode space}

A study by Codrin Lungu et al. [23] was used to estimate the electric conductivity of the perielectrode space under the assumption that it has a characteristic thickness of $250 \mu \mathrm{m}[18,19]$. The electric conductivity was set between 0.01 and $0.2 \mathrm{~S} / \mathrm{m}$ in a parametric sweep in steps of $0.01 \mathrm{~S} / \mathrm{m}$ with a surrounding tissue domain assumed to be a mixture of gray and white matter with a conductivity of $0.09 \mathrm{~S} / \mathrm{m}$. Bipolar stimulation at a voltage, $U$, of $3 \mathrm{~V}$ between contacts 0 and 1 of a 3389 lead (Medtronic Inc., USA) was simulated for the parametric sweep. Modelling and simulation (Fig 1b) was done in Comsol Multiphysics 5.2a (COMSOL, Sweden). For details, see [18]. The impedance, $R(\Omega)$, was calculated according to Ohm's law with the current calculated as the integration of the current density, $\mathbf{J}\left(\mathrm{A} / \mathrm{m}^{3}\right)$, normal to the surface of contact 0 .

$$
R=U /\left|\int \mathbf{n} \cdot \mathbf{J} d S\right|
$$

In the Lungu study, the average measured impedance in the first week after implantation was $1530 \Omega$ and after 3 weeks it had risen to $2530 \Omega$ [23]. The parametric sweep gave corresponding closest impedances of $1551 \Omega$ for a PES conductivity of $0.14 \mathrm{~S} / \mathrm{m}$ 
and $2619 \Omega$ for a PES conductivity of $0.05 \mathrm{~S} / \mathrm{m}$. The PES conductivities of 0.14 and $0.05 \mathrm{~S} / \mathrm{m}$ are thus suitable values to use for the acute and chronic phases respectively.

\section{Discussion}

In this study, suitable rheobase and chronaxie to describe the electric field magnitude threshold, $E F_{\text {t }}$, as well as suitable conductivities of the perielectrode space have been estimated from experimental studies [22, 23].

Hemm et al [24] had associated the $0.1 \mathrm{~V} / \mathrm{mm}$ isolevel from $1.5 \mathrm{~V}$ stimulation to the lateral extent of the GPi in a dystonia patient. However, they had used a very long pulse width of $450 \mu \mathrm{s}$. Putting that pulse width in equation (3) with $E F_{\text {rheo }}=0.098 \mathrm{~V} / \mathrm{mm}$ and $T_{\text {chr }}=62 \mu$ s gives an $E F_{\mathrm{t}}$ of $0.11 \mathrm{~V} / \mathrm{mm}$, in good agreement with the $0.2 \mathrm{~V} / \mathrm{mm}$ level for $60 \mu$ s in this study. Åström et al [12] have studied the impact of the pulse width on $E F_{\mathrm{t}}$ with neuron model simulations. Least squares fitting to their results (Table 3 [12]) gives a $T_{\text {chr }}$ of $100 \mu \mathrm{s}$ (Fig 1a), which would give an $E F_{\text {rheo }}$ of $0.165 /(1+100 / 90)=$ $0.078 \mathrm{~V} / \mathrm{mm}$ and thus an $E F_{\mathrm{t}}$ of $0.078 \cdot(1+100 / 60)=0.21 \mathrm{~V} / \mathrm{mm}$ at $T=60 \mu \mathrm{s}$ when comparing to Kuncel's study [22].

Comparing the $E F_{\mathrm{t}}$ of $0.2 \mathrm{~V} / \mathrm{mm}$ at $60 \mu \mathrm{s}$ with simulations of activation of axons with different fiber diameters [12] indicate that the typical diameter of axons stimulated by DBS should be around $3.5 \mu \mathrm{m}$, which is among the larger axons in the deep brain structures although still smaller than the value of $5.7 \mu \mathrm{m}$ used in many DBS simulation studies [25]. Median axon diameters for different nuclei and white matter tracts have been found to be around $0.5 \mu \mathrm{m}$ in human (range: $0.16-9 \mu \mathrm{m}$ ) and rhesus monkey brains $[26,27]$.

The $250 \mu \mathrm{m}$ thickness of the PES may vary between patients. A larger distance would result in a lower increase in the electric conductivity due to the inflammation/edema and a lower decrease due to the gliosis when estimating the conductivity from measured impedance.

It is interesting to note that the most energy-efficient stimulation occurs at pulse widths equal to the chronaxie [8]. The optimal pulse width to maintain a long battery lifetime is thus the default $60 \mu \mathrm{s}$ when the chronaxie of the triggered tissue is the same as in Rizzone's study [9].

In conclusion, based on the experimental studies used, suitable rheobase and chronaxie for axon activation seem to be $0.98 \mathrm{~V} / \mathrm{mm}$ and $62 \mu$ s respectively, giving a threshold electric field of $0.20 \mathrm{~V} / \mathrm{mm}$ for the default pulse width of $60 \mu \mathrm{s}$. Suitable values for a $250 \mu \mathrm{m}$ PES are $0.14 \mathrm{~S} / \mathrm{m}$ for the acute edema phase and $0.05 \mathrm{~S} / \mathrm{m}$ for the chronic gliosis phase. More experimental studies similar to those of Kuncel [22] and Lungu [23] would be desirable in order to further increase the reliability of these estimates and to see if there are differences in them between different parts of the brain.

\section{Acknowledgements}

This work is funded by the Swedish Research Council (Vetenskapsrådet, Dnr. 201603564), the Swedish Foundation for Strategic Research (Project BD15-0032), and the 
Knut and Alice Wallenberg Foundation (Project Seeing Organ Function). The authors declare that they have no conflicts of interest.

\section{References}

[1] Blomstedt, P., Hariz, G. M., and Hariz, M. I., Pallidotomy versus pallidal stimulation, Parkinsonism Relat Disord, 12(5) pp. 296-301, (2006).

[2] Schuurman, P. R., Bosch, D. A., Merkus, M. P., and Speelman, J. D., Long-term follow-up of thalamic stimulation versus thalamotomy for tremor suppression, Mov Disord, 23(8) pp. 1146-53, (2008).

[3] Eltahawy, H. A., Saint-Cyr, J., Giladi, N., Lang, A. E., and Lozano, A. M., Primary dystonia is more responsive than secondary dystonia to pallidal interventions: Outcome after pallidotomy or pallidal deep brain stimulation, Neurosurgery, 54(3) pp. 613-619, (2004).

[4] Marin, C., Jimenez, A., Tolosa, E., Bonastre, M., and Bove, J., Bilateral subthalamic nucleus lesion reverses L-dopa-induced motor fluctuations and facilitates dyskinetic movements in hemiparkinsonian rats, Synapse, 51(2) pp. 140-50, (2004).

[5] Galarreta, M. and Hestrin, S., Frequency-dependent synaptic depression and the balance of excitation and inhibition in the neocortex, Nat Neurosci, 1(7) pp. 587-94, (1998).

[6] Urbano, F. J., Leznik, E., and Llinás, R. R., Cortical activation patterns evoked by afferent axons stimuli at different frequencies: an in vitro voltage-sensitive dye imaging study, Thalamus \& Related Systems, 1(4) pp. 371-378, (2002).

[7] Brocker, D. T., Swan, B. D., So, R. Q., Turner, D. A., Gross, R. E., and Grill, W. M., Optimized temporal pattern of brain stimulation designed by computational evolution, Sci Transl Med, 9(371) 2017).

[8] Geddes, L. A., Accuracy limitations of chronaxie values, IEEE Trans Biomed Eng, 51(1) pp. 176-81, (2004).

[9] Rizzone, M., Lanotte, M., Bergamasco, B., Tavella, A., Torre, E., Faccani, G., et al., Deep brain stimulation of the subthalamic nucleus in Parkinson's disease: effects of variation in stimulation parameters, J Neurol Neurosurg Psychiatry, 71(2) pp. 215-9, (2001).

[10] Gradinaru, V., Mogri, M., Thompson, K. R., Henderson, J. M., and Deisseroth, K., Optical deconstruction of parkinsonian neural circuitry, Science, 324(5925) pp. 354-9, (2009).

[11] Hassler, R., Riechert, T., Mundinger, F., Umbach, W., and Ganglberger, J. A., Physiological observations in stereotaxic operations in extrapyramidal motor disturbances, Brain, 83 pp. 337-50, (1960).

[12] Åström, M., Diczfalusy, E., Martens, H., and Wårdell, K., Relationship between Neural Activation and Electric Field Distribution during Deep Brain Stimulation, IEEE Transactions on Biomedical Engineering, 62(2) pp. 664-672, (2015).

[13] Hemm, S., Pison, D., Alonso, F., Shah, A., Coste, J., Lemaire, J. J., et al., PatientSpecific Electric Field Simulations and Acceleration Measurements for Objective Analysis of Intraoperative Stimulation Tests in the Thalamus, Front Hum Neurosci, 10 p. 577, (2016). 
[14] Alonso, F., Latorre, M. A., Göransson, N., Zsigmond, P., and Wårdell, K., Investigation into Deep Brain Stimulation Lead Designs: A Patient-Specific Simulation Study, Brain Sciences, 6(3) 2016).

[15] Horn, A., Reich, M., Vorwerk, J., Li, N. F., Wenzel, G., Fang, Q. Q., et al., Connectivity Predicts Deep Brain Stimulation Outcome in Parkinson Disease, Annals of Neurology, 82(1) pp. 67-78, (2017).

[16] Perez-Caballero, L., Perez-Egea, R., Romero-Grimaldi, C., Puigdemont, D., Molet, J., Caso, J. R., et al., Early responses to deep brain stimulation in depression are modulated by anti-inflammatory drugs, Mol Psychiatry, 19(5) pp. 607-14, (2014).

[17] Kozai, T. D., Jaquins-Gerstl, A. S., Vazquez, A. L., Michael, A. C., and Cui, X. T., Brain tissue responses to neural implants impact signal sensitivity and intervention strategies, ACS Chem Neurosci, 6(1) pp. 48-67, (2015).

[18] Alonso, F., Hemm-Ode, S., and Wårdell, K., Influence on Deep Brain Stimulation from Lead Design, Operating Mode and Tissue Impedance Changes - A Simulation Study, Brain Disorders \& Therapy, 4(3) 2015).

[19] Yousif, N., Bayford, R., Bain, P. G., and Liu, X., The peri-electrode space is a significant element of the electrode-brain interface in deep brain stimulation: A computational study, Brain Research Bulletin, 74(5) pp. 361-368, (2007).

[20] Nielsen, M. S., Bjarkam, C. R., Sorensen, J. C., Bojsen-Moller, M., Sunde, N. A., and Ostergaard, K., Chronic subthalamic high-frequency deep brain stimulation in Parkinson's disease - a histopathological study, European Journal of Neurology, 14(2) pp. 132-138, (2007).

[21] Haberler, C., Alesch, F., Mazal, P. R., Pilz, P., Jellinger, K., Pinter, M. M., et al., No tissue damage by chronic deep brain stimulation in Parkinson's disease, Annals of Neurology, 48(3) pp. 372-376, (2000).

[22] Kuncel, A. M., Cooper, S. E., and Grill, W. M., A method to estimate the spatial extent of activation in thalamic deep brain stimulation, Clin Neurophysiol, 119(9) pp. 2148$58,(2008)$.

[23] Lungu, C., Malone, P., Wu, T., Ghosh, P., McElroy, B., Zaghloul, K., et al., Temporal macrodynamics and microdynamics of the postoperative impedance at the tissueelectrode interface in deep brain stimulation patients, J Neurol Neurosurg Psychiatry, 85(7) pp. 816-9, (2014).

[24] Hemm, S., Mennessier, G., Vayssiere, N., Cif, L., and Coubes, P., Co-registration of stereotactic MRI and isofieldlines during deep brain stimulation, Brain Res Bull, 68(12) pp. 59-61, (2005).

[25] McIntyre, C. C., Mori, S., Sherman, D. L., Thakor, N. V., and Vitek, J. L., Electric field and stimulating influence generated by deep brain stimulation of the subthalamic nucleus, Clin Neurophysiol, 115(3) pp. 589-95, (2004).

[26] Liewald, D., Miller, R., Logothetis, N., Wagner, H. J., and Schuz, A., Distribution of axon diameters in cortical white matter: an electron-microscopic study on three human brains and a macaque, Biological Cybernetics, 108(5) pp. 541-557, (2014).

[27] Mathai, A., Wichmann, T., and Smith, Y., More Than Meets the Eye-Myelinated Axons Crowd the Subthalamic Nucleus, Movement Disorders, 28(13) pp. 1811-1815, (2013). 